\title{
Hubungan Bauran Pemasaran dengan Keputusan Pembelian Kaktus di The Prickle House Salatiga Pada Masa Pandemi Covid-19
}

\section{The Relationship Between Marketing Mix And Consumer Buying Decision of Cactus at The Prickle House Salatiga During Covid-19 Pandemic}

\author{
Sinta Nur Riskawati ${ }^{*}$ \\ Yuliawati
}

\author{
Fakultas Pertanian dan Bisnis Universitas Kristen Satya Wacana, Salatiga, Jawa Tengah, \\ Indonesia \\ ${ }^{*}$ Email: 522016060@ student.uksw.edu
}

\begin{abstract}
Marketing mix is a marketing tool where companies use it continuously to achieve marketing objectives in the target market that is divided into 4P namely product, price, place, dan promotion. This study aims to determine the relationship of the marketing mix of internal factors, namely product, price, place and promotion with the consumer buying decision of cactus at The Prickle House Salatiga during the Covid-19 pandemic. The research location is chosen purposively. The types of data used are primary data and secondary data. The type of research used is explanatory research. The sampling was done deliberately to 50 respondents with the criteria of consumers who purchased cactus products during the Covid-19 pandemic since March 2020, posted them on their social media, tagged and reposted by The Prickle House Salatiga. The indicator of the research questionnaire was measured on the Likert scale. The research data will be analyzed statistically with Spearman Rank correlation test. The results showed that the Price, Location, and Promotion variables were significantly correlated with consumer buying decisions. Meanwhile, the product variable is not significantly correlated with the consumer buying decisions.
\end{abstract}

Keywords: marketing mix, 4P, consumer buying decisions, Spearman Rank correlation test

\begin{abstract}
ABSTRAK
Bauran pemasaran merupakan alat pemasaran yang mana perusahaan menggunakannya secara terus-menerus untuk mencapai tujuan pemasaran di pasar sasaran yang dibagi menjadi 4P yaitu product (produk), price (harga), place (lokasi) dan promotion (promosi). Penelitian ini bertujuan untuk mengetahui hubungan bauran pemasaran dari faktor internal yaitu produk, harga, lokasi, dan promosi dengan keputusan pembelian kaktus di The Prickle House Salatiga pada masa pandemi Covid-19. Lokasi penelitian dipilih secara sengaja (purposive). Jenis data yang digunakan adalah data primer dan data sekunder. Jenis penelitian yang digunakan adalah penelitian eksplanasi. Pengambilan sampel dilakukan secara sengaja kepada 50 responden dengan kriteria konsumen yang membeli produk kaktus pada masa pandemi Covid-19 sejak bulan Maret 2020, mempostingnya di
\end{abstract}


media sosial mereka, menandai dan direpost oleh The Prickle House Salatiga. Indikator kuesioner penelitian diukur dengan skala Likert. Data penelitian akan dianalisis secara statistik dengan uji korelasi Rank Spearman. Hasil penelitian menunjukkan bahwa variabel Harga, Lokasi, dan Promosi berkorelasi secara signifikan dengan keputusan pembelian. Sedangkan, variabel Produk berkorelasi tidak signifikan dengan keputusan pembelian.

Kata kunci: bauran pemasaran, 4P, keputusan pembelian, uji korelasi Rank Spearman

\section{PENDAHULUAN}

Kebutuhan akan tanaman hias merupakan kebutuhan sekunder bagi masyarakat. Fungsi tanaman hias yang beraneka ragam seperti hanya sekedar sebagai penghijau ruangan, sebagai properti atau sebagai hobi memberikan prospek yang baik bagi masa depan bisnis tanaman hias. Salah satu tanaman hias yang sedang menjadi trend digemari banyak kalangan saat ini adalah kaktus. Selain perawatannya yang mudah, kaktus juga memberikan kesan minimalis saat digunakan sebagai hiasan ruangn. Kaktus juga sering digunakan sebagai properti pemanis saat pengambilan gambar produk para online shop.

Kota Salatiga yang berada di Jawa Tengah juga mengalami trend tanaman kaktus membuat banyak wirausaha memulai bisnis pada tanaman hias kaktus. Salah satu diantaranya adalah The Prickle House Salatiga, sebuah rumah usaha yang menyediakan berbagai macam jenis tanaman kaktus dalam pot untuk keperluan hiasan dan mengedepankan nilai estetika. The Prickle House Salatiga juga melakukan promosi melalui sosial media dan kegiatan bazar guna mengembangkan usaha dan meningkatkan penjualan.

Pandemi Covid-19 yang terjadi membawa dampak pada berbagai sektor di masyarakat, salah satunya adalah The Prickle House Salatiga yang mengalami penurunan permintaan. Berkurangnya konsumen The Prickle House Salatiga berdampak pada omset yang mengalami penurunan hingga $75 \%$. Oleh karena itu, diperlukan strategi pemasaran yang tepat untuk mengatasi masalah tersebut. Bauran pemasaran atau marketing mix dapat mempengaruhi keputusan konsumen dalam proses pembelian. Penelitian tentang bauran pemasaran sangat penting dilakukan guna mengetahui variabel dalam bauran pemasaran apakah berhubungan dengan keputusan pembelian kaktus. Variabel bauran pemasaran tersebut meliputi produk, harga, lokasi, promosi.

Kotler (2012), menyatakan pemasaran sebagai proses di mana perusahaan menciptakan nilai bagi pelanggan dan membangun hubungan yang kuat dengan pelanggan, dengan tujuan menangkap nilai dari pelanggan sebagai imbalannya. Salah satu cara untuk memenangkan pasar adalah melalui perencanaan teknis. Menurut Shinta (2011) perencanaan teknis yang dapat digunakan adalah bauran pemasaran yang merupakan perangkat alat pemasaran taktis yang dapat dikembalikan dan dipadukan oleh perusahaan untuk menghasilkan respon yang diinginkan pasar sasaran. Menurut Kotler (2012) bauran pemasaran merupakan alat pemasaran yang mana perusahaan menggunakannya secara terus-menerus untuk mencapai tujuan pemasaran di pasar sasaran yang dibagi menjadi 4P yaitu product (produk), price (harga), place (lokasi) dan promotion (promosi). Bauran pemasaran harus dapat bersifat dinamis dan dapat menyesuaikan diri dengan lingkungan eksternal yaitu faktor di luar jangkauan perusahaan yang terdiri dari pesaing, teknologi, 
peraturan pemerintah, keadaan perekonomian dan lingkungan sosial budaya. Selain faktor eksternal, ada pula faktor internal yaitu variabel-variabel yang terdapat dalam bauran pemasaran antara lain, produk, harga, promosi, dan lokasi pemasaran. Berdasarkan uraian tersebut, penelitian ini bertujuan untuk mengetahui hubungan bauran pemasaran dari faktor internal yaitu produk, harga, lokasi, dan promosi dengan keputusan pembelian kaktus di The Prickle House Salatiga pada masa pandemi Covid-19.

\section{METODOLOGI PENELITIAN}

Lokasi penelitian di The Prickle House Salatiga dipilih secara sengaja (purposive) dengan pertimbangan berkurangnya pembeli dan minat konsumen untuk membeli kaktus di The Prickle House Salatiga yang berdampak pada penurunan omset hingga $75 \%$ saat pandemi Covid-19. Jenis data yang digunakan adalah data primer dan sekunder. Data primer dikumpulkan secara langsung menggunakan kuesioner dari 50 responden yang membeli produk kaktus pada masa pandemi Covid-19 sejak bulan Maret 2020, memposting produk yang dibeli pada media sosial responden, menandai media sosial The Prickle House Salatiga dan direpost oleh The Prickle House Salatiga. Data sekunder diperoleh dari studi literatur seperti jurnal, buku dan penelitian terdahulu. Jenis penelitian yang digunakan adalah penelitian eksplanasi (explanatory research). Sugiyono (2016) menjelaskan penelitian eksplanasi digunakan untuk menjelaskan kedudukan-kedudukan dari variabelvariabel yang diteliti serta hubungan antara satu variabel dengan variabel lainnya. Dalam penelitian ini yang diuji adalah hubungan antara variabel bebas yaitu produk, harga, promosi, lokasi dengan variabel terikat keputusan pembelian.

Variabel-variabel yang digunakan dalam penelitian diberikan penjelas batasan-batasan agar tidak menimbulkan penafsiran yang berbeda. Definisi operasional dalam penelitian dijabarkan dalam Tabel 1.

Tabel 1. Definisi Operasional Variabel Penelitan

\begin{tabular}{lll}
\hline Variabel & \multicolumn{1}{c}{ Definisi } & \multicolumn{1}{c}{ Indikator } \\
\hline Produk & Suatu barang yang ditawarkan untuk memenuhi & 1. Ragam produk \\
& keinginan dan kebutuhan konsumen. & 2. Kualitas \\
& & 3. Nama merek \\
& & 4. Kemasan \\
Harga & Jumlah nilai yang harus dikeluarkan konsumen untuk & 5. Ukuran \\
& mendapatkan produk dan layanan. & 1. Daftar harga \\
Lokasi & Kegiatan pemasaran yang dilakukan perusahaan & 1. Pilihan lokasi \\
& untuk mempermudah proses penyaluran barang dari & 2. Persediaan \\
& produsen ke konsumen. & transportasi \\
& & 3. Fasilitas \\
Promosi & Kegiatan perusahaan yang dilakukan untuk & 1. Pemasaran langsung \\
& memperkenalkan produknya kepada konsumen. & 2. Periklanan \\
Keputusan & Pemahaman konsumen tentang keinginan dan & 1. Pengenalan \\
Pembelian & kebutuhan akan suatu produk dengan menilai dari & kebutuhan \\
& sumber-sumber yang ada dengan menetapkan tujuan & 2. Pencarian informasi \\
& pembelian serta mengidentifikasi alternatif sehingga & 3. Pelaksanaan \\
& pengambil keputusan untuk membeli yang disertai & pembelian \\
& dengan perilaku setelah melakukan pembelian. & 4. Perilaku pasca \\
& & pembelian \\
\hline
\end{tabular}


Penentuan nilai variabel produk, harga, promosi, lokasi dan keputusan pembelian diukur menggunakan indikator-indikator dalam bentuk pernyataan dengan skala Likert yang terdiri dari 5 skor yaitu skor 1 = sangat tidak setuju (STS); 2 = tidak setuju (TS); 3 = raguragu (RR); 4 = setuju (S); dan 5 = sangat setuju (SS). Instrumen penelitian akan diuji kelayakannya menggunakan uji validitas dan uji reliabilitas. Data penelitian akan dianalisis secara statistik dengan uji korelasi Rank Spearman. Nilai rs diinterpretasikan sebagai berikut; jika nilai $|\mathrm{rs}|=0$ maka kedua variabel tidak berkorelasi; namun jika nilai $|\mathrm{rs}|=1$ maka kedua variabel berkorelasi sempurna. Semakin tinggi nilai $|\mathrm{rs}|$ maka semakin kuat hubungan kedua variabel. Tanda positif pada nilai rs menunjukkan bahwa kedua variabel berkorelasi searah, yakni bila variabel $\mathrm{X}$ semakin tinggi, maka variabel $\mathrm{Y}$ akan cenderung semakin tinggi, dan sebaliknya. Untuk memudahkan melakukan interpretasi mengenai kekuatan hubungan antara dua variabel, Sugiyono (2016) menyusun kriteria sebagai berikut, jika nilai koefisien korelasi Rank Spearman (rs):

$0,00-0,19$ : Korelasi sangat lemah

$0,20-0,39$ : Korelasi lemah

$0,40-0,59$ : Korelasi sedang

$0,60-0,79$ : Korelasi kuat

$0,80-1,00:$ Korelasi sangat kuat

Uji tingkat signifikasi koefisien korelasi (rs) ditetapkan angka signifikansi sebesar 5\%, karena hipotesis penelitian dua arah sehingga angka signfikansi sebesar 2,5\%. Kriteria pengambilan keputusan sebagai berikut:

Jika angka signifikansi hasil analisis $<0,025$, maka hubungan kedua variabel signifikan. Jika angka signifikansi hasil analisis > 0,025, maka hubungan kedua variabel tidak signifikan.

\section{HASIL DAN PEMBAHASAN}

Hasil analisis korelasi Rank Spearman hubungan antara produk, harga, lokasi, dan promosi dengan keputusan pembelian kaktus The Prickle House Salatiga disajikan pada Tabel 2.

Tabel 2. Hasil Analisis Korelasi Rank Spearman

\begin{tabular}{lcccc}
\hline Variabel & rs & Sig. & Tingkat kekuatan hubungan & Keterangan \\
\hline Produk & 0,227 & 0,113 & Lemah & Tidak signifikan \\
Harga & 0,424 & 0,002 & Sedang & Signifikan \\
Lokasi & 0,545 & 0,000 & Sedang & Signifikan \\
Promosi & 0,406 & 0,003 & Sedang & Signifikan \\
\hline
\end{tabular}

Sumber : Hasil Analisis Data Responden

Hasil pengujian hipotesis Tabel 1 menunjukkan bahwa:

1. Hubungan Produk Dengan Keputusan Pembelian Kaktus di The Prickle House Salatiga

Berdasarkan hasil analisis Korelasi Rank Spearman dapat diketahui hubungan produk dengan keputusan pembelian memiliki nilai 0,227 berarti tingkat kekuatan hubungan antara variabel produk dengan keputusan pembelian kaktus adalah lemah (nilai rs berada pada rentang 0,20 - 0,39). Angka signifikansi sebesar 0,113>0,025 menunjukkan hubungan antara variabel produk dengan keputusan pembelian tidak signifikan. Tanda positif menunjukkan hubungan searah. 
Hubungan antara produk dengan keputusan pembelian yang tidak signifikan menunjukkan bahwa ragam maupun kualitas produk yang rendah ataupun tinggi tidak memiliki hubungan dengan keputusan pembelian kaktus. Hal tersebut didukung hasil penelitian Pardede dan Haryadi (2017) tentang Pengaruh Persepsi Harga dan Kualitas Produk Terhadap Keputusan Pembelian Konsumen yang Dimediasi Kepuasan Konsumen yang menyatakan bahwa kualitas produk tidak mempengaruhi keputusan pembelian konsumen. Tanda positif menunjukkan semakin baik produk kaktus yang dijual oleh The Prickle House Salatiga akan semakin tinggi konsumen memutuskan pembelian kaktus, demikian juga sebaliknya. Hasil penelitian ini juga sesuai dengan penelitian Ria dan Yuliawati (2018) yang menyatakan meningkatnya kualitas sebuah produk maka akan meningkat pula keputusan pembelian konsumen. Kualitas produk yang diberikan merupakan strategi yang tepat untuk menarik perhatian konsumen. Masa pandemi Covid19 membuat konsumen kini lebih mempertimbangkan keputusan mereka dalam mempergunakan uang, sehingga konsumen seringkali melihat suatu produk dari sosial media terlebih dahulu sebelum membeli. Maka perlunya kesesuaian kualitas antara katalog produk di sosial media dengan produk aslinya. Suatu usaha yang selalu memiliki inovasi pada produknya akan membuat konsumen tidak jenuh dan memiliki alternatif dalam melakukan keputusan pembelian.

2. Hubungan Harga Dengan Keputusan Pembelian Kaktus di The Prickle House Salatiga Berdasarkan hasil analisis Korelasi Rank Spearman dapat diketahui hubungan antara harga dengan keputusan pembelian memiliki nilai 0,424 berarti tingkat kekuatan hubungan antara variabel harga dengan keputusan pembelian kaktus adalah sedang (nilai rs berada pada rentang 0,40 - 0,59). Angka signifikansi sebesar 0,002 $<0,025$ menunjukkan hubungan antara variabel harga dengan keputusan pembelian signifikan. Tanda positif menunjukkan hubungan searah.

Hasil penelitian menunjukkan bahwa semakin tinggi harga yang ditetapkan oleh The Prickle House Salatiga maka akan semakin menarik konsumen untuk melakukan pembelian. Hal ini didukung oleh penelitian yang dilakukan Irawati dan Nuswantara (2019) tentang Hubungan Marketing Mix Terhadap Keputusan Konsumen Sayuran Hidroponik Di Crispy Farm Kecamatan Banyumanik Kabupaten Semarang dan penelitian yang dilakukan Santi, dkk. (2020) tentang Keputusan Pembelian Sayur Organik Pada Gerai Jual Di Kota Denpasar yang menyatakan bahwa terdapat hubungan yang signifikan dan positif antara harga dengan keputusan pembelian. Hal ini menunjukkan bahwa harga yang ditetapkan oleh The Prickle House Salatiga sudah terjangkau sehingga berpengaruh terhadap keputusan pembelian.

Bagi konsumen pembelian pertama, harga tidak menjadi pertimbangan. Namun untuk pembelian selanjutnya, harga menjadi pertimbangan yang sangat diperhatikan oleh konsumen. Oleh karena itu, responden juga menyatakan bahwa pemberian diskon mendorong mereka untuk membeli kaktus. Persepsi terhadap harga suatu produk akan berbeda tiap individu. Hal tersebut dikarenakan latar belakang ekonomi dan lingkungan setiap individu berbeda, ditambah dengan kondisi pandemi Covid-19 yang mempengaruhi perekonomian di masyarakat. Harga yang tinggi ataupun rendah tetapi tidak sesuai dengan kualitas produk yang diharapkan, akan membuat konsumen merasa kecewa. Menurut Nurhayati (2017) bagi sebagian konsumen, yang terpenting adalah kesesuaian produk dengan keinginan mereka atau produk keluaran terbaru yang sedang 
menjadi trend. The Prickle House selama pandemi Covid-19 juga menambah jenis produk yang dijual untuk mengikuti trend tanaman hias yang terjadi selama pandemi.

3. Hubungan Lokasi Dengan Keputusan Pembelian Kaktus di The Prickle House Salatiga

Berdasarkan hasil analisis Korelasi Rank Spearman dapat diketahui hubungan antara lokasi dengan keputusan pembelian memiliki nilai 0,545 berarti tingkat kekuatan hubungan antara variabel lokasi dengan keputusan pembelian kaktus adalah sedang (nilai rs berada pada rentang $0,40-0,59)$. Angka signifikansi sebesar $0,000<0,025$ menunjukkan hubungan antara variabel lokasi dengan keputusan pembelian signifikan. Tanda positif menunjukkan hubungan searah.

Hasil penilitian menunjukkan bahwa semakin strategis lokasi pemasaran The Prickle House Salatiga akan semakin banyak konsumen yang datang dan melakukan pembelian. Hal ini didukung oleh penelitian yang dilakukan oleh Ria dan Yuliawati (2018) tentang Hubungan Harga, Lokasi, Kualitas Produk, Kualitas Pelayanan dan Lingkungan Dengan Keputusan Pembelian Susu Segar Di Kecamatan Sidorejo, Salatiga, Jawa Tengah dan penelitian yang dilakukan Bangun dan Nuswantara (2020) tentang Hubungan Antara Marketing Mix Dengan Keputusan Pembelian Sayuran Hidroponik Di Kios Granari Fresh Semarang yang menyatakan bahwa lokasi memiliki hubungan yang signifikan dengan keputusan pembelian.

The Prickle House Salatiga memiliki lokasi penjualan yang cukup strategis karena berada dipinggir jalan, sehingga konsumen dapat dengan mudah menjangkau lokasi tersebut. Lahan parkir yang disediakan juga cukup luas, sehingga dapat menampung pengunjung yang cukup banyak. Tersedianya fasilitas cuci tangan dan toilet membuat konsumen merasa lebih nyaman ketika datang langsung di tengah pandemi seperti ini. Sesuai dengan pendapat Tjiptono (2006) yang menyatakan bahwa lokasi usaha maupun produk yang dijual haruslah mudah dilihat atau dijangkau sarana transportasi umum, hal tersebut yang kemudian menjadi pertimbangan konsumen untuk memutuskan membeli produk yang ditawarkan. Oleh karena itu, pemilihan lokasi sangat penting yang akan berpengaruh pada keberhasilan suatu usaha, sebab berhubungan dengan keputusan pembelian konsumen.

4. Hubungan Promosi Dengan Keputusan Pembelian Kaktus di The Prickle House Salatiga

Berdasarkan hasil analisis Korelasi Rank Spearman dapat diketahui hubungan antara promosi dengan keputusan pembelian memiliki nilai 0,406 berarti tingkat kekuatan hubungan antara variabel promosi dengan keputusan pembelian kaktus adalah sedang (nilai rs berada pada rentang 0,40 - 0,59). Angka signifikansi sebesar 0,003 $<0,025$ menunjukkan hubungan antara variabel promosi dengan keputusan pembelian signifikan. Tanda positif menunjukkan hubungan searah.

Hasil penelitian menunjukkan bahwa semakin baik promosi yang dilakukan oleh The Prickle House Salatiga maka akan semakin menarik konsumen untuk datang dan membeli kaktus. Artinya promosi yang diberikan oleh The Prickle House melalui media sosial, spanduk ataupun bazar sudah sesuai dengan tujuannya yaitu menarik konsumen. Hal ini didukung penelitian yang dilakukan Bangun dan Nuswantara (2020) tentang Hubungan Antara Marketing Mix Dengan Keputusan Pembelian Sayuran Hidroponik Di Kios 
Granari Fresh Semarang yang menyatakan bahwa promosi memiliki arah hubungan yang positif dengan keputusan pembelian.

Selama masa pandemi Covid-19, The Prickle House Salatiga lebih fokus untuk melakukan promosinya melalui sosial media. The Prickle House Salatiga kini lebih memaksimalkan sosial media mereka untuk meningkatkan jumlah pembelian. Smith (2011) menyatakan bahwa promosi merupakan segala jenis komunikasi persuasif antara satu fungsi pemasaran atau lebih terhadap konsumen potensial yang bertujuan baik langsung maupun tidak untuk meningkatkan kemungkinan pembelian barang atau jasa. Titley (2011) menyatakan promosi dirancang untuk mempengaruhi perilaku konsumen dan keputusan pengeluarannya, menyadarkan konsumen akan suatu merek, tempat penjualan, serta harga jual produk tersebut.

\section{SIMPULAN DAN SARAN}

\section{Simpulan}

Berdasarkan hasil analisis dan pembahasan di atas, maka dapat diperoleh kesimpulan hubungan antara bauran pemasaran dengan pembelian kaktus di The Prickle House Salatiga pada masa pandemi Covid-19 sebagai berikut : (a) hubungan produk dengan keputusan pembelian kaktus lemah, tidak signifikan dan searah; (b) hubungan harga dengan keputusan pembelian kaktus sedang, signifikan dan searah; (c) hubungan lokasi dengan keputusan pembelian kaktus sedang, signifikan dan searah; (d) hubungan promosi dengan keputusan pembelian kaktus sedang, signifikan dan searah.

\section{Saran}

The Prickle House Salatiga untuk lebih memperhatikan produk-produk yang ditawarkan agar menjadi salah satu pertimbangan konsumen dalam melakukan pembelian kaktus. Konsumen menyukai jenis-jenis kaktus yang unik dan sedang trend sehingga penjual harus selalu berusaha menyediakan produk-produk yang dicari konsumen. Terutama pada masa pandemi Covid-19 terjadi lonjakan trend tanaman hampir di seluruh Indonesia, sehingga The Prickle House dapat mengambil kesempatan tersebut untuk meningkatkan penjualan. Pada hasil penelitian dapat dilihat bahwa produk, harga, lokasi dan promosi tidak memiliki hubungan yang kuat dengan keputusan pembelian kaktus, sehingga untuk penelitian selanjutnya diharapkan untuk mengkaji lebih dalam tentang faktor-faktor lainnya dalam pemasaran yang memiliki hubungan dengan keputusan pembelian konsumen. Selain itu, pada kuesioner harus dicantumkan usia, pekerjaan dan pendapatan bulanan. Usia agar mengetahui kelompok usia konsumen yang paling banyak datang membeli kaktus, sedangkan pekerjaan dan pendapatan bulanan agar mengetahui latar belakang ekonomi konsumen yang paling banyak datang membeli kaktus di The Prickle House Salatiga.

\section{DAFTAR PUSTAKA}

Bangun, P. A., dan Nuswantara, B. 2020. Hubungan Antara Marketing Mix Dengan Keputusan Pembelian Sayuran Hidroponik Di Kios Granari Fresh Semarang. Agrika, 14(1), 1-10. 
Irawati, K., dan Nuswantara, B. 2019. Hubungan Marketing Mix Terhadap Keputusan Konsumen Sayuran Hidroponik Di Crispy Farm Kecamatan Banyumanik Kabupaten Semarang. Agritech: Jurnal Fakultas Pertanian Universitas Muhammadiyah Purwokerto, 21(1), 21-31.

Nurhayati, S. 2017. Pengaruh Citra Merek, Harga Dan Promosi Terhadap Keputusan Pembelian Handphone Samsung Di Yogyakarta. Jurnal Bisnis, Manajemen, dan Akuntansi, 4(2). 60-69.

Pardede, R., dan Haryadi, T. Y. 2017. Pengaruh Persepsi Harga Dan Kualitas Produk Terhadap Keputusan Pembelian Konsumen Yang Dimediasi Kepuasan Konsumen. Journal of Business \& Applied Management, 10(1). 55-79.

Kotler, Philip. 2012. Prinsip-Prinsip Pemasaran Edisi 13. Jilid 1. Jakarta: Erlangga.

Ria, R., dan Yuliawati, Y. (2018). Hubungan Harga, Lokasi, Kualitas Produk, Kualitas Pelayanan Dan Lingkungan Dengan Keputusan Pembelian Susu Segar Di Kecamatan Sidorejo, Salatiga, Jawa Tengah. Jurnal Sosial Ekonomi Pertanian, 14(3), 195-209.

Santi, N.K.R.D., Antara, M., dan Widhianthini. 2020. Keputusan Pembelian Sayur Organik Pada Gerai Jual Di Kota Denpasar. Jurnal Manajemen Agribisnis (Journal Of Agribusiness Management), 8(1), 102-110.

Shinta, Agustina. 2011. Manajemen Pemasaran. Malang: Universitas Brawijaya Press (UB Press).

Smith, M. 2011. Fundamentals of Management. Berkshire: McGraw-Hill education.

Sugiyono. 2016. Metode Penelitian dan Pengembangan (Research and Development/R\&D). Bandung: Alfabeta.

Titley, B. 2011. Complete Business Studies for Cambridge IGCSE \& O Level. New York: Oxford University Press.

Tjiptono, F. 2006. Strategi Pemasaran. Yogyakarta: Andi Offset. 